number of other developments, such as threedimensional relaxation, heat conduction, and other problems, are discussed in the final chrpter. The book is rounded off with a bibliography concerned with relaxation methods, an index: of the sixty-two problems solved in the two-volume publication, a list of the authors mentioned in the book, and a separate index of the topics discussed in the treatise.

The excellence of the printing, of the many line drawings and of the general display makes it neces. sary to comment once again, even at the risk of appearing monotonous, on the valuable service which the Clarendon Press is rendering to scientists, and to the reputation of British scientific printing, by maintaining its perfectionist standards.

Lastly, a special tribute to Sir Richard Southwell - for the idea, for its development, for the vision to see its great value, and for his three excellent books. Something of the strength of the creative urge to write this last book may be sensed from the fact that the author relinquished his post of rector of the Imperial College of Science and Technology in order to make leisure for himself to complete the work. But perhaps the greatest tribute comes from the work itself-for the ugliness of some of the problems which he describes becomes transformed into elegance when treated by the 'method of relaxation'.

Louis Rosenhead

\section{NUCLEAR PHYSICS FOR THE RESEARCH WORKER}

\section{The Atomic Nucleus}

By Prof. Robley D. Evans. (International Series in Pure and Applied Physics.) Pp. xv + 972. (London: McGraw-Hill Publishing Company, Ltd., 1955.) $109 s$.

DROF. R. D. EVANS is a distinguished physicist, well known for his studies of naturally occurring radioelements and for his work on ebsorption coefficients and the units and standards of radioactivity. That he is also an outstanding teacher is obvious from this book, in which is assembled the material of lectures in nuclear physics given to graduate students of the Massachusetts Institute of Technology over the past twonty years. At a time when books in this general field seem to be written mainly by theorists, the appearance of a text which firmly adopts the experimental point of view is especially welcome. The reader will, however, not find more than a passing reference to the details of experimental methods; the aim and virtue of this book are to set out, in a clear and unhurried manner, the general principles of the subject, particularly those which are often glossed over or obscured in more hasty treatments of greater scope. The book abounds in precise definitions of terms such as 'radius' and 'cross-section' and should contribute materially to the systematization of nuclear terminology.

The first part of the book is devoted to the main nuclear properties of charge, radius, mass, static moments, parity and statistics. These chapters lead up to discussions of nuclear binding energy, internucleon forces, nuclear models and nuclear reactions. The treatment is careful and thorough, at a level which seems admirable for the general purposes of the graduate student, and there is particular emphasis on the physical interpretation of theoretical ideas.
The main theoretical framework is wave-mechanical and the word 'matrix' does not occur in the index. Most of the more importent derivations, such as those relating to expansions in partial waves and to barrier penetration, are given in detail, sometimes in appendixes.

In the second half of the book Prof. Evans treats the radioactive-series decay, alpha- and beta-spectra and the interaction of charged particles and of electromagnetic radiation with matter. The chapters on these latter subjects, perhaps because of the author's personal interests, are really short expert monographs and are more highly developed, and therefore somewhat less easy to read, than the earlier parts of the book. The final chapters include useful accounts of the application of statistical methods in nuclear physics, including the fashionable 'chi-square' test. There are tables of constants and appendixes giving formulæ for the centre-of-mass system and for relativistic problems. The book is enriched by an impressive collection of useful exercises and problems, many of which themselves contain new and interesting facts.

The reader can scarcely fail to admire the care and thought which Prof. Evans has bestowed on this work, and he will probably put down the book with a feeling of regret that even in nearly one thousand pages it has still not been possible to touch on anything like all the manifold divisions of the subject. The title is carefully chosen, and the exclusion of practically the whole vast area of high-energy physics is perhaps to be expected, but the student might have hoped for more guidance regarding the theoretical spectroscopy of light nuclei or the interpretation of reaction data according to the shell models. Lifetime determinations and Coulomb excitation processes are also among the subjects which should figure in a future edition. The topics included are, however, the important ones and the research worker proceeding to his more narrow specialization will be grateful to the author for the sound foundations laid in this volume. The book has gained much from the labours of two decades of students and appears, at first reading, to be wholly free from errors. Pedagogically, its publication is an important event for the nuclear physicist in training, but its appeal as a general handbook should be much wider and most workers in the subject may expect to derive pleasure and profit from reading it.

W. E. Burcham

\section{BASIC IDEAS IN TOPOLOGY}

\section{Elementary Topology}

By Prof. Dick Wick Hall and Prof. Guilford L. Spencer. Pp. xii +303. (New York : John Wiley and Sons, Inc.; London: Chapman and Hall, Ltd., 1955.) 56s, net.

\section{Topology}

By Dr. E. M. Patterson. (University Mathematical Texts.) Pp. viii +128 . (Edinburgh and London: Oliver and Boyd, Ltd. ; New York: Interscience Publishers, Inc., 1956.) 8s. 6d. net.

7 HESE two books deal with the elements of topology for the undergraduate in an honours course, and have much ground in common; they are, however, to some extent complementary, one to the other. A novice reading Hall and Spencer might end with a respectable knowledge of the jergon and 